\title{
OPTIMAL PLACEMENT OF BASE STATION FOR CELLULAR NETWORK EXPANSION
}

\author{
Siddharth.A. Karulkar, Texas A\&M University Kingsville, sidkarulkar@gmail.com \\ Joon-Yeoul Oh, Texas A\&M University Kingsville, joon-yeoul.oh@tamuk.edu
}

\begin{abstract}
A cellular network optimization is extremely important to provide consumers with satisfactory signal strength and high coverage. For an optimized cellular network, the location of a base station is paramount importance which should be considered by geographic as well as topographic features. The objective of this research is to find best base station location in cellular network expansion while considering the coverage and avoiding areas. The city of Kingsville, TX was selected for study. To achieve this objective, Geographic Information Systems software and Non Linear Programming technique are used.
\end{abstract}

Keywords: Cellular Network Expansion, Optimization, Geographical Information Systems, Non Linear Programming

\section{INTRODUCTION}

Cellphones has evolved significantly since 1983, both in design and function. Dr. Martin Cooper, a former Motorola employee acquainted the world to the first cell phone on April 3, 1974. He dialed a base station across the street from the New York Hilton hotel (Fuentelsaz, Maicas \& Polo, 2008).

The modern-day cellular technology began to flourish in the 90s (Viswanathan \& Weldon, 2003). The technology that modifies cell phones from radio is the use of cells and the way they are associated (Mshvidobadze, 2012). The cell tower is the mediator between the cellphones at the receiving and the calling ends. A cellphone typically consist of a radio transmitter and a receiver for sending and receiving radio signals respectively (Poole, 2016).

Exponential increase in consumers and inadequate capacity of the prevailing cellular communication network limit a clear and constant reception. For expansion of existing cell communication network capacity, an optimal placement of cellular tower is important to setup an efficient system that no area is left uncovered or poorly covered (Alenoghena \& Emagbetere, 2012).

\section{BASIC COMPONENTS OF CELLULAR COMMUNICATION NETWORK}

The concept of cellular communication is very similar to the working of a cordless phone. A cellular tower and a base station are engineered to cover a larger geographic region than your home; they can handle hundreds of cellphones simultaneously, can operate in multiple radio frequencies and allows the caller to switch different base stations while in motion (Harris, 2011).

Towers, cells, hexes are the building blocks of a wireless communication network. Cells are geographic coverage area of a cellular tower. The towers are placed in such a way that multiple cells form a tight knit mesh (Harris, 2011). Four basic components of a cellular mobile network are mobile station, base station, mobile switching center and public switched telephone network. The mobile station creates a network between mobile subscriber and the base station whereas the base station handles the call traffic to and fro from the mobile subscribers in their respective cells. The mobile switching center is structured to connect the base station to the public switching telephone network. The PSTN creates a path between the calling and the caller party and maintains the link till the duration of the call (Fallis, 2012). 


\section{LITERATURE REVIEW}

Optimal allocation of Base stations can be treated as resource allocation problems, which consider factors such as heights and locations of buildings, transmitting power and attenuation through walls. The objective function is to maximize the coverage area and the decision variables are base station locations, height, number of base stations required (Lee, Mazumdar \& Shroff, 2006). Optimized placement of any entity requires a strategic planning, taking into consideration various criteria's.

Specific geographic information, distribution of current customers, population shift, transport infrastructure. Base stations are allocated while considering the user distribution, user movement, channel occupancy and handover (Yamada \& Barolli, 2001). Outdated laws for land acquisition, topography etc. plays a role in deciding the placement of Base station (Alenoghena \& Emagbetere,2012). Base station location can be optimized by maximizing the lifetime of sensor network and minimizing the total energy consumption of the nodes (Tripathi, Dhuli, Singh \& Verma, 2014).

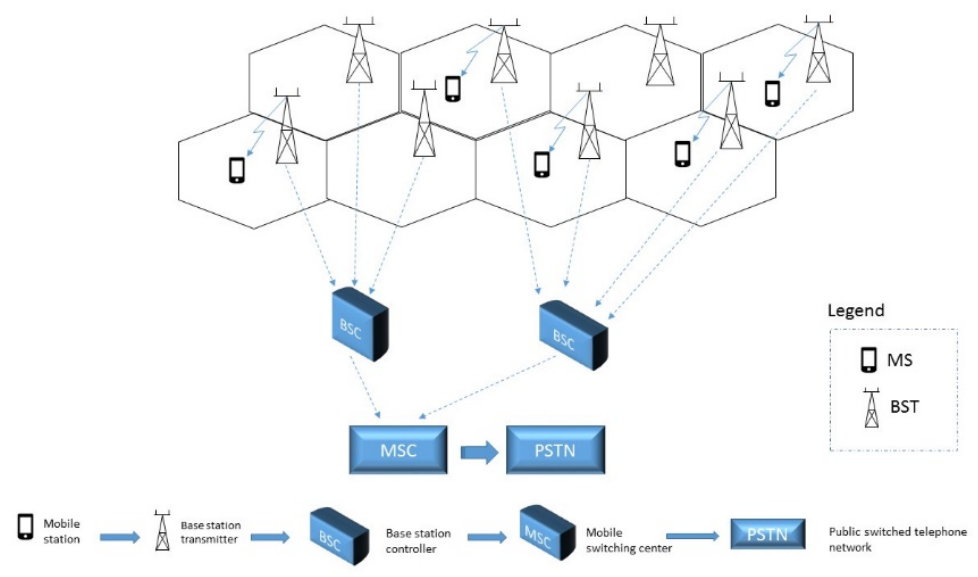

Figure 1. Cellular Network

Since last few decades, professionals from various fields have been employing GIS techniques for research and planning. GIS helps to sketch the geographic terrain and other geographic data and can display spatial features and locations, compare two spatial locations. Powerful database exposes the user to a vast set of data. Environmental scientists, planning and resource managers make utmost use of GIS (Jiehai \& Shidong, 2010).

The integration of geographic, environmental factors along with the population factor benefits the concept of telemedicine which uses modern telecommunication for remote monitoring of patients' health. GIS helps to identify the epidemiological data. It visualizes the data which allows the professionals to map public health care centers and other related facilities accordingly. Integration of all such data helps to monitor and manage diseases. The database can be used for further reference and surveillance (Bramanti, Bonanno, Celona, Bertuccio, Calisto, Lanzafame \& Bramanti, 2010).

NLP is used to find the most suitable location using optimization techniques (Lee, Mazumdar \& Shroff, 2006). Suitable sites for installing cellphone towers can be found out using geographic information system software (GIS). GIS helps in identifying avoidable and restricted areas (Bramanti, Bonanno, Celona, Bertuccio, Calisto, Lanzafame \& Bramanti, 2010). 


\section{MAPPING USING GIS}

The city of Kingsville, TX was selected for applying this research. The area around Texas A\&M universityKingsville within one mile radius from the center of the university was studied. There are eight towers located in the city. The figure 2 shows the boundary and raster image of city of Kingsville of the city.

\section{Trimble GPS Analyst}

A mapping and surveying instrument called "Trimble GPS Analyst" is an extension for ArcGIS with tools to manage GPS data. It was used to record the coordinates of every cellular tower individually. Trimble unit uses Arc $\mathrm{Pad}$ as an interface which is software used for mobile GIS and field mapping applications. Figure 2 (a) shows the political boundary and map in figure 2 (b) shows a raster image of city of Kingsville.

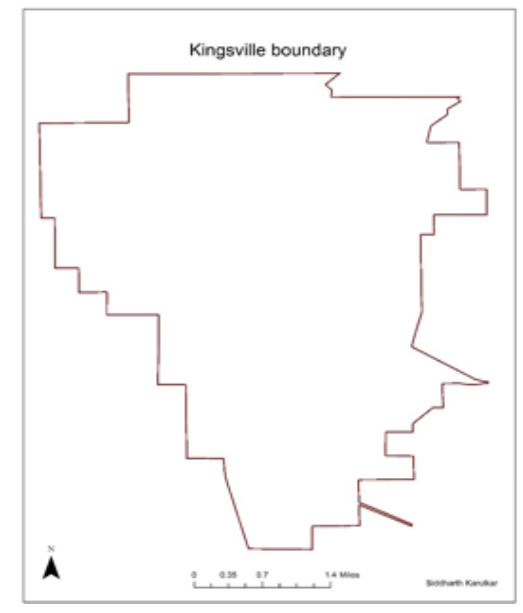

(a)

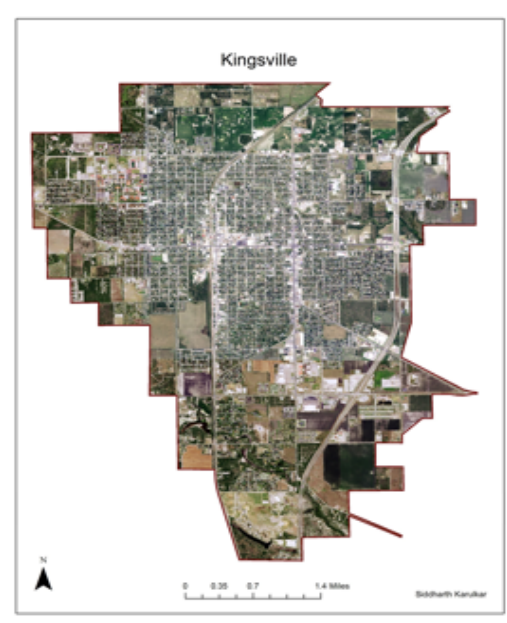

(b)

Figure 2. Political Boundary and Raster Image of City of Kingsville

\section{Mapping the current location using ArcGIS}

A base-map for Kleberg County was downloaded from the website, www.tenris.org. Using the clipping tool, the base-map was reduced to the city of Kingsville. The shapefile generated on the Trimble GPS Analyst was loaded on this map using ArcGIS. After loading the shapefile, the location of the cellular towers is clearly visible in figure 3.

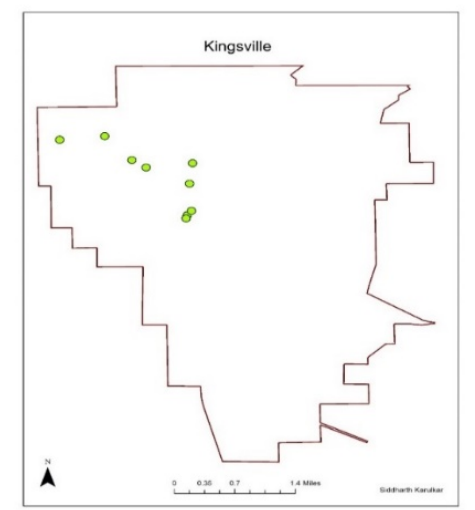

Figure 3. Cellular Towers in Kingsville 


\section{Selecting a location for cellular tower without geographical hindrance}

The following features of area should be considered for selecting a location of cellular tower.

1. Roads should be identified for accessibility.

2. The land cover should be identified to avoid inaccessible areas.

3. Population distribution plays a major role.

\section{Creating base-maps}

The following base-maps were created using ArcGIS.

1. Kingsville boundary with roads.

2. Population density of Kingsville.

3. Land cover of Kingsville.

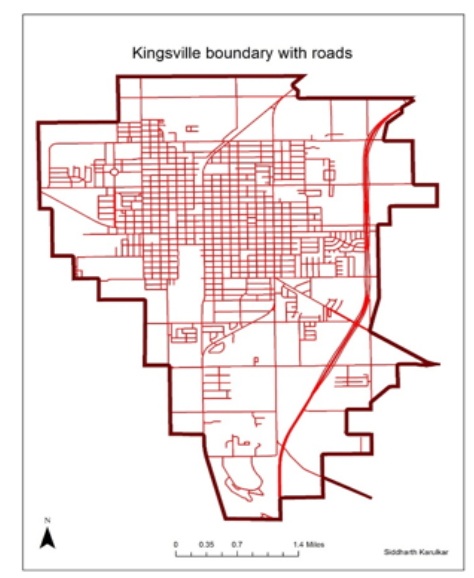

(a)

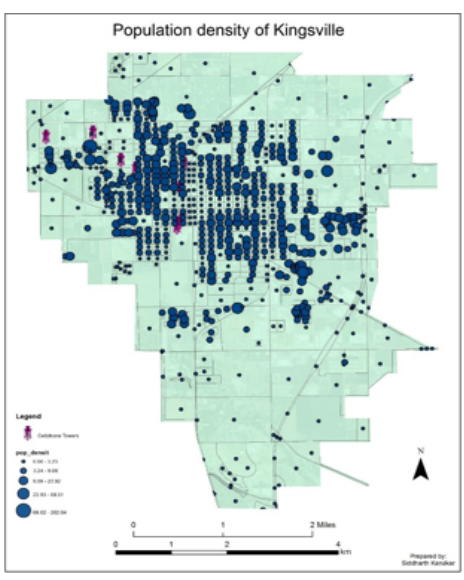

(b)

Figure 4. Roads and Population Distribution

The map in figure 4 (a) shows the information about the roads and the transport links in the city of Kingsville. It is extremely important that the cellular tower should be accessible for repairs, maintenance and construction work. This map is useful to understand the accessibility to the cellular towers. This map gives detailed information about streets and the state highways which the city of Kingsville includes. The roads are shown in red color. The boundary of city of Kingsville is shown by thick brown color. A state highway passing through the city is clearly visible.

Cellular towers are inevitably linked with the population density. The map in figure 4 (b) shows the population distribution of the city. The cellular tower distribution for urban area is different from that of the distribution in a city. The area which is crowded would need more number of towers whereas the areas less populated would need less number of cellular towers. It is important to understand the distribution of the population and its density. 


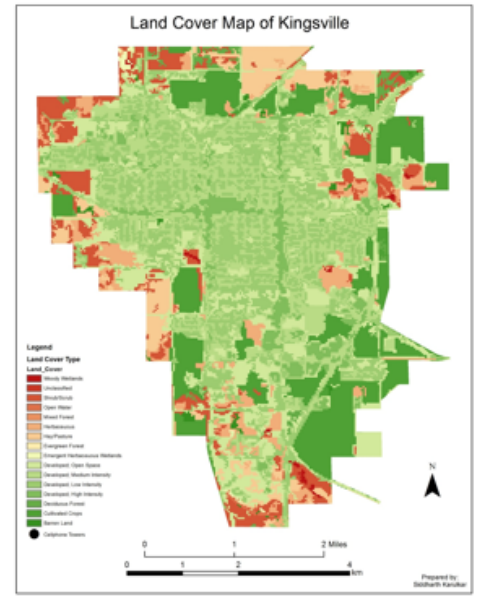

(a)

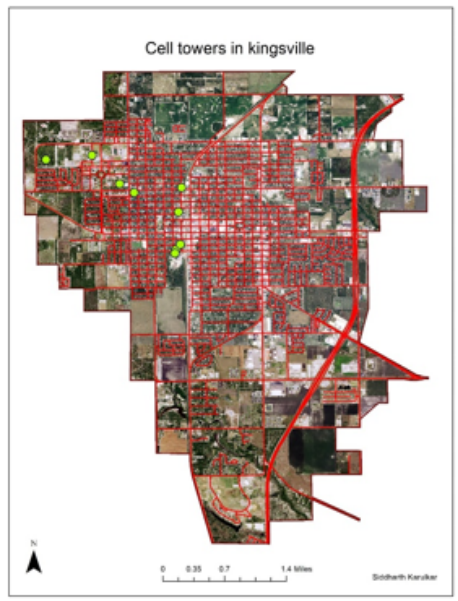

(b)

Figure 5. Land Cover and Cellular Towers in Kingsville

Land cover of city of Kingsville can have a significant impact on placement of cellular towers for cellular network expansion. The land cover map confirms how much of a region is covered by forest, wetlands, agriculture, developed land etc. Cellular towers cannot be placed on wet lands and areas under federal jurisdiction. The most appropriate land for placing a cellular tower can be easily identified using a land cover map in figure 5 (a).

The map in figure 5 (b) aggregates few base layers such as the roads layer, the raster layer for city of Kingsville, the boundary layer and the cellular tower location layer. This map gives a brief idea about the location of the towers, their accessibility from the nearest road etc.

\section{Exporting the map}

Once the final map (figure 5) is ready, it is exported in a .jpeg version for further use. It can be exported in different versions too. Essential features such as title, legend, north arrow, name of scale bar.

\section{SELECTION OF LOCATION USING NLP}

NLP technique is applied to find the optimal location for cellular tower. The Location of the power plant must satisfy the requirements that are formulated as NLP. There are major criteria in selecting suitable location for celllar tower.

1. Accessibility of cellular tower location to increase the ease of maintenance and construction work.

2. Achievement of optimal coverage and optimal distance between two cellular towers.

3. The range of the towers should effectively cover the populated area for better service.

The followings are the variables used in the NLP model.

$\left(q_{X}, q_{Y}\right)$ : Coordinates of the TAMUK.

$\left(w_{X}, w_{Y}\right)$ : Coordinates of possible locations to set up cellular tower.

$\left(b_{X}, b_{Y}\right)$ : Coordinates of possible location of first resident area to set up cellular tower

$\left(c_{X}, c_{Y}\right)$ : Coordinates of possible location of second resident area to set up cellular tower

$\left(e_{i X}, e_{i Y}\right):$ Coordinates selected in the wetlands, where $i=1,2, \ldots$

$\left(r_{i X}, r_{i Y}\right):$ Coordinates of the water bodies, where $i=1,2, \ldots$

$\left(t_{i X}, t_{i Y}\right):$ Coordinates of the points on road, where $i=1,2, \ldots$

$\left(v_{i X}, v_{i Y}\right):$ Coordinates of the cellular towers, where $i=1,2, \ldots$ 
Then, the objective function becomes:

$$
\operatorname{Min} \sqrt{\left(q_{X}-w_{X}\right)^{2}+\left(q_{Y}-w_{Y}\right)^{2}}+\sqrt{\left(q_{X}-b_{X}\right)^{2}+\left(q_{Y}-b_{Y}\right)^{2}}+\sqrt{\left(q_{X}-c_{X}\right)^{2}+\left(q_{Y}-c_{Y}\right)^{2}}
$$

The possible location should satisfy the following constraints:

- Wet lands: The power plant should be located in a certain distance, $\varepsilon$, from wetlands, where $\varepsilon=0.4 \mathrm{Km}$.

$$
\sqrt{\left(q_{X}-e\right)^{2}+\left(q_{Y}-e_{i Y}\right)^{2}} \geq \varepsilon
$$

- Water body: The power plant should be located in a certain distance, $\rho$, from water body, where $\rho=0.4 \mathrm{Km}$.

$$
\sqrt{\left(q_{X}-r_{i X}\right)^{2}+\left(q_{Y}-r_{i Y}\right)^{2}} \geq \rho
$$

- Roads: The power plant should be located in a certain distance, $\tau$, from roads, where $\tau=0.04 \mathrm{Km}$ and it should not exceed distance, $\eta$, where $\eta=0.05 \mathrm{~km}$

$$
\eta \geq \sqrt{\left(q_{X}-t_{i X}\right)^{2}+\left(q_{Y}-t_{i Y}\right)^{2}} \geq \tau
$$

- Cellular towers: The cellular towers should be located in a certain distance, $\zeta$, from each other, where $\zeta=1.83 \mathrm{Km}$ and it should not exceed distance, $\varpi$, where $\varpi=3.2 \mathrm{~km}$

$$
\zeta \geq \sqrt{\left(q_{X}-v_{i X}\right)^{2}+\left(q_{Y}-v_{i Y}\right)^{2}} \geq \varpi
$$

\section{CONCLUSION}

This paper discussed about allocation of cellular towers for expansion of current cellular network. To get the optimized location, GIS and NLP techniques were used. GIS helps in identifying the areas to be avoided, waterbodies, inaccessible terrain resident areas etc. An NLP technique helps in identifying the best location. To accomplish this approach in reality, addition of tasks such as cost of land, technical limitations and other barriers should be considered.

\section{REFERENCES}

Alenoghena, C. O., \& Emagbetere, J. O. (2013). Base station placement challenges in cellular networks: The Nigerian experience, IEEE 4th Int. Conf. Adapt. Sci. Technol. ICAST Beppu city, Oita, Japan pp. 7-11.

Bramanti, A., Bonanno, L., Celona, A., Bertuccio, S., Calisto, A., Lanzafame, P. \& P. Bramanti, (2010). GIS and spatial analysis for costs and services optimization in neurological telemedicine, Annu. Int. Conf. IEEE Eng. Med. Biol. Soc. EMBC'10, Buenos Aires, Argentina, pp. 2204-2207.

Fallis. A (2012). Principles of mobile communication, J. Chem. Inf. Model., (53), pp. 1689-1699, 2012

Fuentelsaz, L., Maicas, J. P. and Polo, Y., (2008) The evolution of mobile communications in Europe: The transition from the second to the third generation, Telecomm. Policy, 32(6), pp. 436-449.

Harris, B. Y. M. (2011). How Cell Towers Work, [online] Available: http://www.unisonsite.com/pdf/resourcecenter/How\%20Towers\%20Work.pdf

Islam, M. H., Dziong, Z., Sohraby, K., Daneshmand, M. F. \& Jana, R., (2012). Capacity-optimal relay and base station placement in wireless networks, The Int. Conf. on Information Network, Bali, Indonesia, pp. 358363.

Jiehai, C. \& Shidong, W (2010). Research on Analysis of Site Selection of the University Supermarket Based on SuperMap GIS, Second Int. Conf. Multimed. Inf. Technol., Kaifeng, Henan, China, pp. 282-284. 
Lee, J. W., Mazumdar, R. \& Shroff, N. (2016). Joint resource allocation and base-station assignment for the downlink in CDMA networks, IEEE/ACM Trans. Netw., 14(1), pp. 1-14.

Mshvidobadze, T. (2012). Evolution mobile wireless communication and LTE networks, 6th Int. Conf Appl. Inf. Commun. Technol., Tbilisi, GA, pp. 1-7.

Mustafa, I. S., Din, N. M., Ismail, A., Omar, R.C. \& Khalid, N. H. N (2013). Antenna placement for landslide monitoring using Analytical Hierarchy Process (AHP) and Geographical Information System (GIS), IEEE Symp. Wirel. Technol. Appl., Kuching, Malaysia, pp. 295-300.

Poole, I. (2016). Cell phone electronics basics, [online] Available: http://www.radioelectronics.com/info/cellulartelecomms/cellular_concepts/cell-phone-electronicsbasics.php

Pulido, B., Alonso-Gonzalez, C., Gonzalez, E., Barredo, C., Lopez, M., Corzo, J., \& Calvo, J. A. (2013) GIS-based DSS for optimal placement for oceanic power generation: OCEANLIDER project, Spanish coastline study, Int. Conf. Renew. Energy Res. Appl. ICRERA, Madrid, Spain, pp. 137-142.

Tripathi, R. K., Dhuli, S., Singh, Y. N. \& N. K. Verma (2014). Analysis of weights for optimal positioning of base station in a Wireless Sensor Network, 20th Natl. Conf. Commun. NCC, (5), Kanpur, India, pp. 2-5.

Viswanathan, H. \& Weldon, M. (2003) .The past, present, and future of mobile communications, Bell Labs Technical Journal, 19, pp. 8-21.

Yamada, T. \& Barolli, L. (2001). A Simulation Study for Allocation of Base Stations in Mobile Communication Networks, 15th Int. Conf. Information Networking, Beppu city, Oita, Japan, pp. 32-37. 